\title{
The effect of microstructure on the electrical properties of $\mathrm{NiO}$-doped $\mathrm{BaTiO}_{3}$
}

\author{
W.H. Tzing ${ }^{\mathrm{a}}$, W.H. Tuan ${ }^{\mathrm{a}, *}$, H.L. Lin ${ }^{\mathrm{b}}$ \\ anstitute of Materials Science and Engineering, National Taiwan University, Taipei, Taiwan \\ ${ }^{\mathrm{b}}$ Department of Materials Engineering, Tatung Institute of Technology, Taipei, Taiwan \\ Received 21 January 1998; accepted 16 May 1998
}

\begin{abstract}
A small amount of $\mathrm{NiO}$ may dissolve into $\mathrm{BaTiO}_{3}$ during the co-firing of $\mathrm{BaTiO}_{3}$ based dielectrics and Ni internal electrodes. In the present study, the effect of $\mathrm{NiO}$ addition on the microstructure and the electrical properties of $\mathrm{BaTiO}_{3}$ is investigated. The microstructure is observed by scanning electron microscopy and transmission electron microscopy. The formation of eutectic liquid phase may degrade the relative permittivity at room temperature of undoped $\mathrm{BaTiO}_{3}$. The presence of $\mathrm{NiO}$ solute reduces both the size of $\mathrm{BaTiO}_{3}$ grains and the width of $90^{\circ}$ domain. The relative permittivity at room temperature is increased with the decrease of $\mathrm{BaTiO}_{3}$ grain size. The electrical resistivity also increases with the decrease of grain size. It is due to the enhancement of grain boundary resistivity by the $\mathrm{Ni}$ solute. The $\mathrm{NiO}$ inclusions can inhibit the grain growth of $\mathrm{BaTiO}_{3}$. However, the relative permittivity and electrical resistivity of $\mathrm{NiO}$ are low; the relative permittivity and electrical resistivity of $\mathrm{NiO}-\mathrm{doped} \mathrm{BaTiO}_{3}$ is thus decreased with the increase of $\mathrm{NiO}$ inclusions. (C) 1999 Elsevier Science Limited and Techna S.r.l. All rights reserved.
\end{abstract}

Keywords: B. Microstructure; C. Electrical properties; D. $\mathrm{BaTiO}_{3}$

\section{Introduction}

The electrical properties of $\mathrm{BaTiO}_{3}$ depend strongly on its microstructure. For example, the relative permittivity of $\mathrm{BaTiO}_{3}$ reaches its highest value as its grain size is around $1 \mu \mathrm{m}$ [1]. The high permittivity was related to the decrease $90^{\circ}$ domain amount [2] or to the decrease of $90^{\circ}$ domain width [1]. The electrical resistivity, Curie temperature and the relative permittivity at Curie temperature of $\mathrm{BaTiO}_{3}$ are all affected by its microstructure.

The microstructure of $\mathrm{BaTiO}_{3}$ can be controlled by two approaches. One approach uses novel processing techniques to tailor the microstructure [3,4]. Another approach uses grain growth inhibitors to prohibit the grain growth. The second approach has been proved to be a useful one [5-9]. For example, a small addition of $\mathrm{Dy}_{2} \mathrm{O}_{3}$ [5] or $\mathrm{Nb}_{2} \mathrm{O}_{5}$ [6] or $\mathrm{SC}_{2} \mathrm{O}_{3}$ [7] or $\mathrm{Ta}_{2} \mathrm{O}_{5}$ [8] or $\mathrm{ZnO}$ [9] can all prohibit the abnormal grain growth.

$\mathrm{BaTiO}_{3}$ and its related compounds are frequently used as high-permittivity capacitor materials. For multilayer ceramic capacitors, $\mathrm{Ag}-\mathrm{Pd}$ alloys are usually used

\footnotetext{
* Corresponding author.
}

as internal electrodes. $\mathrm{Ni}$ is used recently to replace the Ag-Pd alloys for the cost of the Ag-Pd alloys is high [10]. Nickel may be oxidized during the powder processing and the subsequent co-firing with $\mathrm{BaTiO}_{3}$ in a protective atmosphere. A recent study indicated that a small amount of $\mathrm{NiO}$ can dissolve into $\mathrm{BaTiO}_{3}$ as it is fired with $\mathrm{NiO}$ at $1100^{\circ} \mathrm{C}$ in air for $1 \mathrm{~min}$ [11]. It is thus important to investigate the effect of $\mathrm{NiO}$ on the electrical properties of $\mathrm{BaTiO}_{3}$. In the present study, $\mathrm{NiO}$ is mixed intimately with $\mathrm{BaTiO}_{3}$ and sintered in air. The relationships between the microstructure and electrical properties of the $\mathrm{NiO}$-doped $\mathrm{BaTiO}_{3}$ are investigated.

\section{Experimental}

Barium titanate powder (no. 216-9, Ferro Co., USA) and various amount of nickel nitrate (Johnson Matthey Chem. Co., USA) were tumble milled together in ethyl alcohol for $4 \mathrm{~h}$. The $\mathrm{Ba} / \mathrm{Ti}$ ratio of the $\mathrm{BaTiO}_{3}$ powder is 0.995 as reported by the manufacturer. The grinding media used was zirconia balls. The slurry of the powder mixtures was dried using a rotary evaporator. The dried 
lumps were then crushed and passed through a plastic sieve. As-sieved powder was calcined in air at $500^{\circ} \mathrm{C}$ for $1 \mathrm{~h}$. The powder was formed into disks by pressing uniaxially at $25 \mathrm{MPa}$. The size of the discs is $10 \mathrm{~mm}$ in diameter and about $5 \mathrm{~mm}$ in thickness. Sintering was performed in air at 1290 to $1370^{\circ} \mathrm{C}$ for $2 \mathrm{~h}$ with a muffle furnace (Lindberg/Blue Co., USA). The heating and cooling rates were $3^{\circ} \mathrm{C} / \mathrm{min}$.

The final density was determined by the water displacement method. The polished specimens were prepared by grinding with $\mathrm{SiC}$ particles and polishing with $\mathrm{Al}_{2} \mathrm{O}_{3}$ particles. The grain boundary and domain structure were revealed by etching with a dilute solution of $\mathrm{HCl}$ and $\mathrm{HF}$. The microstructure was observed by scanning electron microscopy (SEM). The grain size was determined by using the line intercept method. Samples for transmission electron microscopy (TEM) observation were dimpled and ion-milled to form a thin section. Phase identification was performed by X-ray diffractometry (XRD). The dielectric properties were measured by a LCZ meter (BP 4272A, Hewlett Packard Co., USA) with a $1 \mathrm{~V}$ signal at $1 \mathrm{k} \mathrm{Hz}$. Silver paste was applied as electrodes. The testing temperature was varied from room temperature to $165^{\circ} \mathrm{C}$. The electrical resistivity was measured by using a two-probe method with a constant voltage of 50 volts at room temperature.

\section{Results and discussion}

\subsection{Microstructure characterization}

The XRD analysis reveals only tetragonal $\mathrm{BaTiO}_{3}$ in the doped $\mathrm{BaTiO}_{3}$ containing less than $1 \mathrm{wt} \% \mathrm{NiO}$. It is due to a small amount $\mathrm{NiO}$ is dissolved into $\mathrm{BaTiO}_{3}[11]$

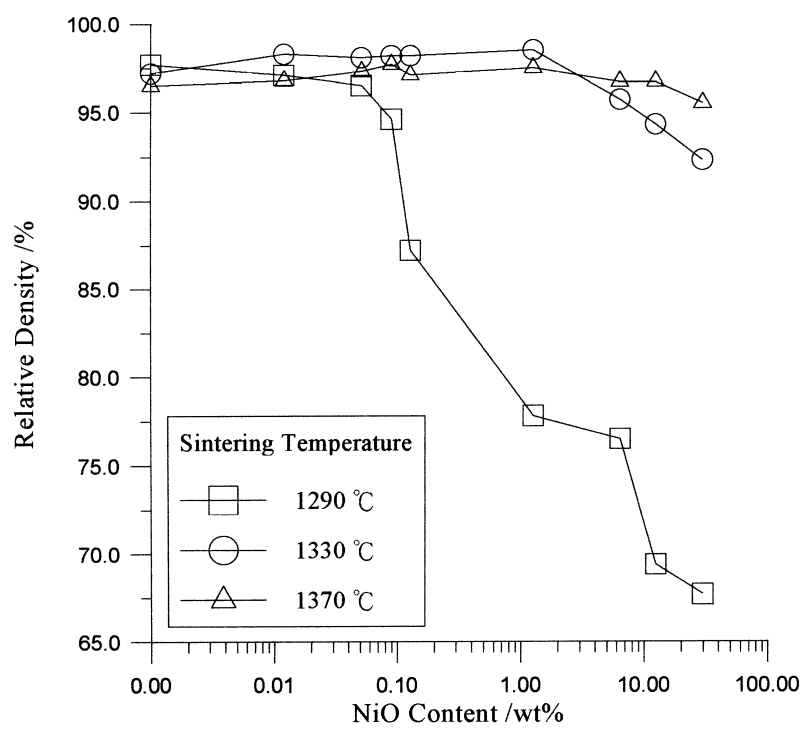

Fig. 1. The relative density of $\mathrm{NiO}$-doped $\mathrm{BaTiO}_{3}$ as a function of $\mathrm{NiO}$ content.

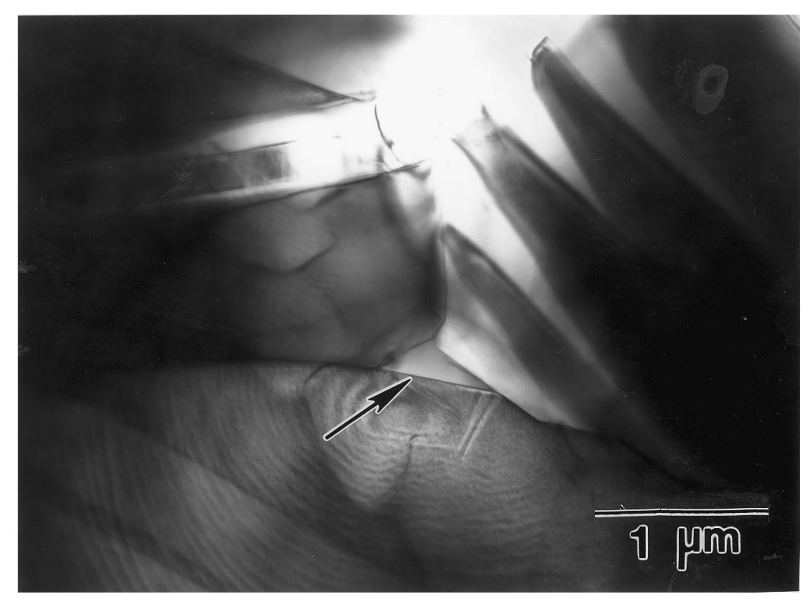

(a)

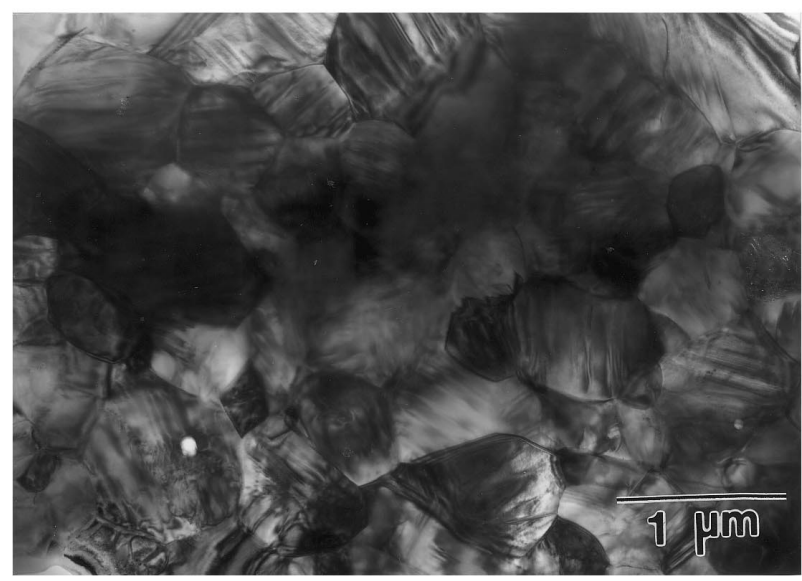

(b)

Fig. 2. TEM micrographs of an (a) undoped and a (b) $0.13 \mathrm{wt} \% \mathrm{NiO}-$ doped $\mathrm{BaTiO}_{3}$. The sintering temperature is $1330^{\circ} \mathrm{C}$. The liquid phase is indicated with an arrow.

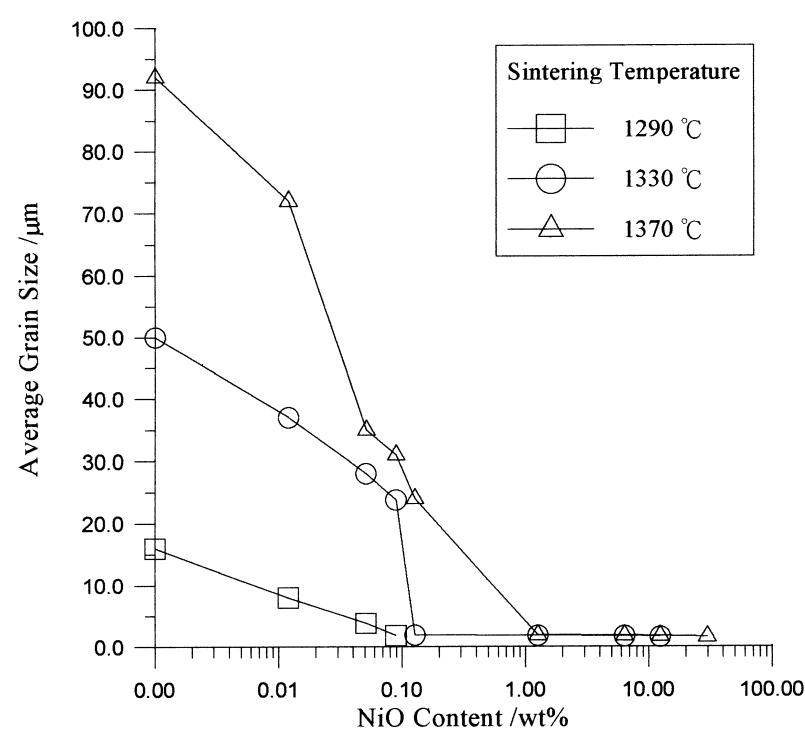

Fig. 3. The grain size of NiO-doped $\mathrm{BaTiO}_{3}$ as a function of $\mathrm{NiO}$ content. 
and $1 \mathrm{wt} \%$ is below the detection limit of the XRD technique. Cubic $\mathrm{NiO}$ is found in the doped $\mathrm{BaTiO}_{3}$ containing more than $1 \mathrm{wt} \% \mathrm{NiO}$. A monoclinic phase, $\mathrm{Ba}_{6} \mathrm{Ti}_{17} \mathrm{O}_{40}$, is found in the specimens sintered at $1370^{\circ} \mathrm{C}$. The presence of $\mathrm{Ba}_{6} \mathrm{Ti}_{17} \mathrm{O}_{40}$ phase indicates the presence of eutectic liquid phase during sintering [12].

The relative density of the NiO-doped $\mathrm{BaTiO}_{3}$ is shown as a function of $\mathrm{NiO}$ content in Fig. 1. The microstructures of undoped $\mathrm{BaTiO}_{3}$ and $0.13 \mathrm{wt} \% \mathrm{NiO}-$ doped $\mathrm{BaTiO}_{3}$ are shown in a Fig. 2. The liquid phase can also be observed in the specimens sintered at $1330^{\circ} \mathrm{C}$, Fig. 2(a). It is due to the eutectic temperature for $\mathrm{TiO}_{2}$-rich region of the $\mathrm{BaO}-\mathrm{TiO}_{2}$ system is around $1312^{\circ} \mathrm{C}$ [12]. The presence of the liquid phase enhances the densification; the density of the specimens sintered at 1330 and $1370^{\circ} \mathrm{C}$ is thus higher than that of the specimens sintered at $1290^{\circ} \mathrm{C}$ (Fig. 1). Since the amount of $\mathrm{Ba}_{6} \mathrm{Ti}_{17} \mathrm{O}_{40}$ phase is small, there is no $\mathrm{Ba}_{6} \mathrm{Ti}_{17} \mathrm{O}_{40}$ phase detected by XRD analysis in the specimens sintered at $1330^{\circ} \mathrm{C}$. The $\mathrm{NiO}$ second phase inclusions are presented in the doped $\mathrm{BaTiO}_{3}$ containing more than $0.13 \mathrm{wt} \% \mathrm{NiO}[11]$. The presence of second phase inclusions can inhibit the densification [13]. The density of the $\mathrm{NiO}$-doped $\mathrm{BaTiO}_{3}$ sintered at $1290^{\circ} \mathrm{C}$ is thus decreased with the increase of $\mathrm{NiO}$ content. To compare

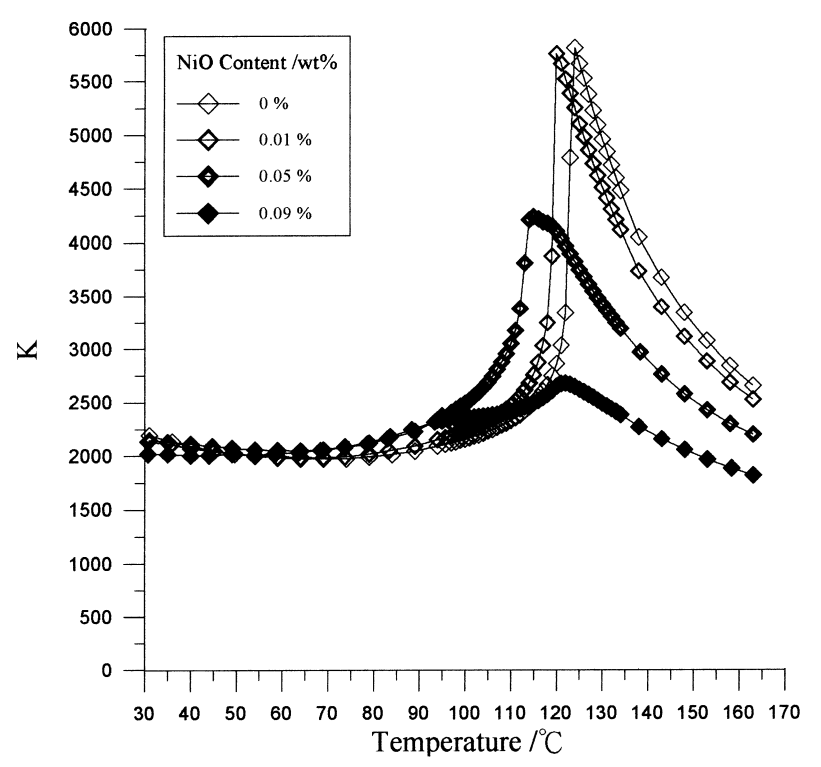

(a)

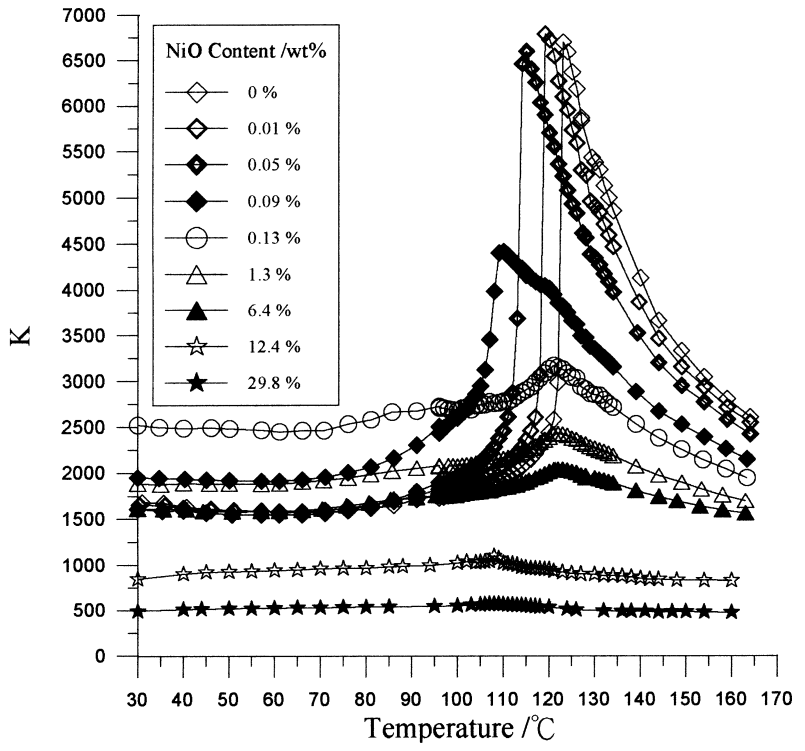

(b)

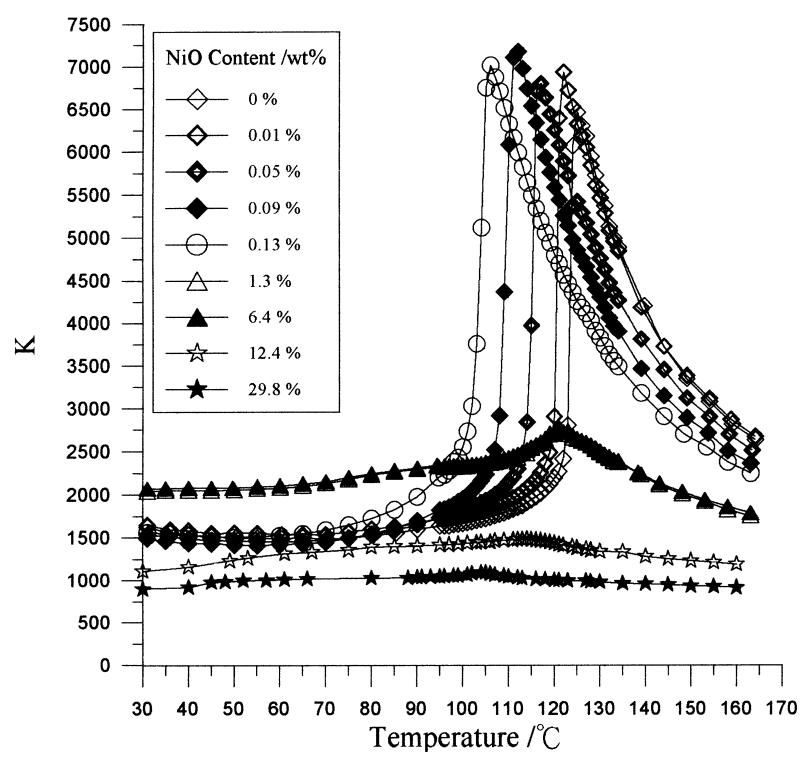

(c)

Fig. 4. The relative permittivity $(K)$ as a function of temperature and $\mathrm{NiO}$ content. The specimens are sintered at (a) $1290^{\circ} \mathrm{C},(\mathrm{b}) 1330^{\circ} \mathrm{C}$ and (c) $1370^{\circ} \mathrm{C}$. 
the electrical properties of $\mathrm{NiO}$-doped $\mathrm{BaTiO}_{3}$ in a relatively narrow density range, only the specimens with relative density higher than $94 \%$ are investigated in the present study.

The grain size of NiO-doped $\mathrm{BaTiO}_{3}$ is shown as a function of $\mathrm{NiO}$ content in Fig. 3. Both the Ni solute and $\mathrm{NiO}$ second phase can inhibit the grain growth of $\mathrm{BaTiO}_{3}$. In summary, specimens with the density ranging from 94 to $99 \%$ are obtained in the present study. The grain size of the specimens varies from 1 to $100 \mu \mathrm{m}$. For most of the specimens, there is a liquid phase located at the grain boundaries.

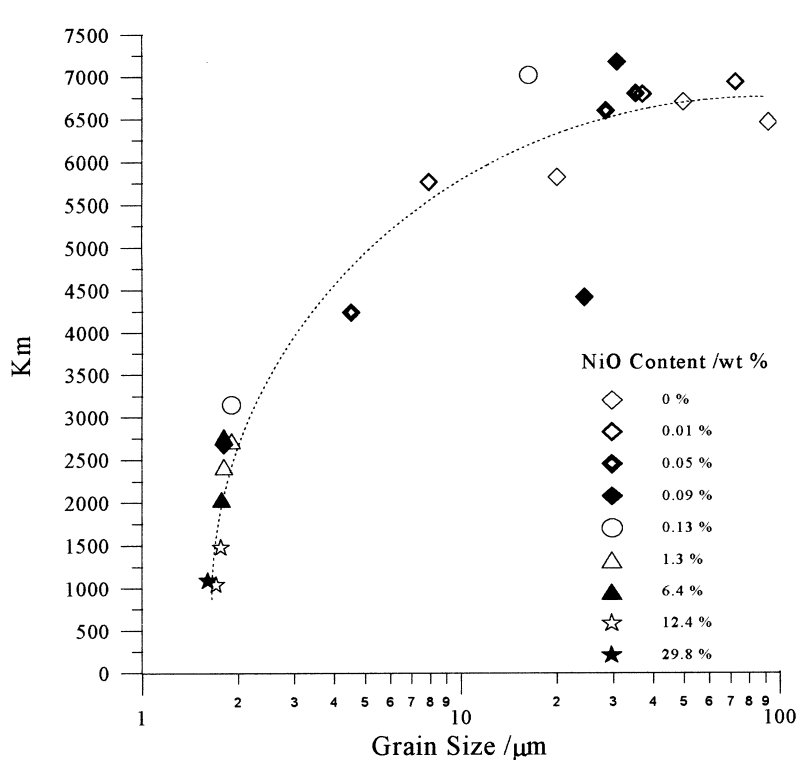

Fig. 5. The relative permittivity at Curie temperature $(\mathrm{Km})$ as a function of grain size.

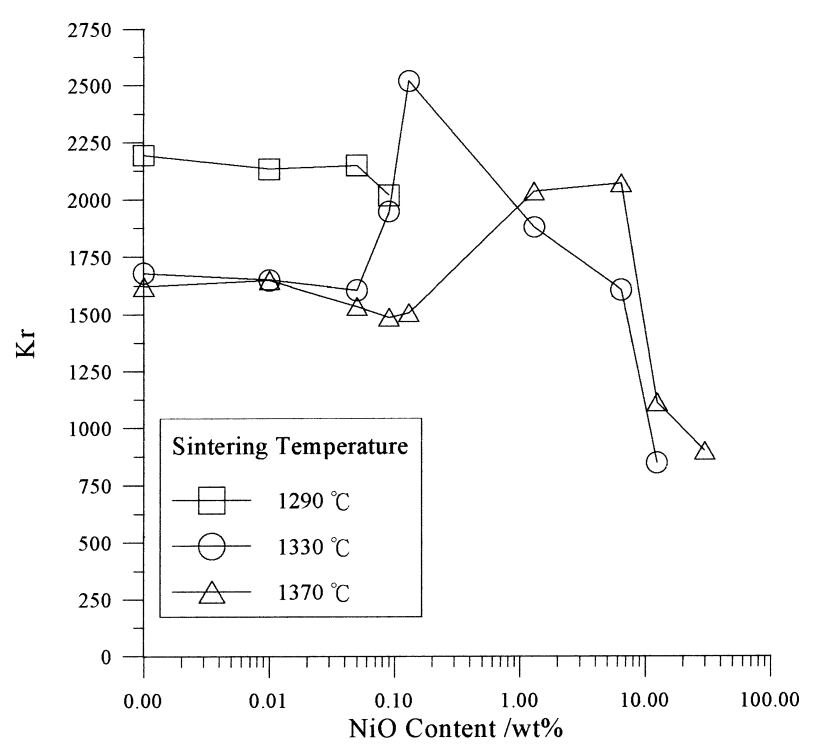

Fig. 6. The relative permittivity at room temperature $(\mathrm{Kr})$ of NiOdoped $\mathrm{BaTiO}_{3}$ as a function of $\mathrm{NiO}$ content.

\subsection{Electrical properties - microstructure relationships}

The permittivity-temperature curves for the NiOdoped $\mathrm{BaTiO}_{3}$ are shown in Fig. 4. Each point in the permittivity-temperature curves was obtained by holding the specimens at each temperature for $9 \mathrm{~min}$. The Curie temperature decreases with the increase of $\mathrm{NiO}$ content as the $\mathrm{NiO}$ content is below the solubility limit. The decrease can be related to the solution of $\mathrm{Ni}$ in $\mathrm{BaTiO}_{3}[14,15]$. As the NiO content is above the solubility limit, the relative permittivity is less sensitive to the change of temperature. The flat permittivity-

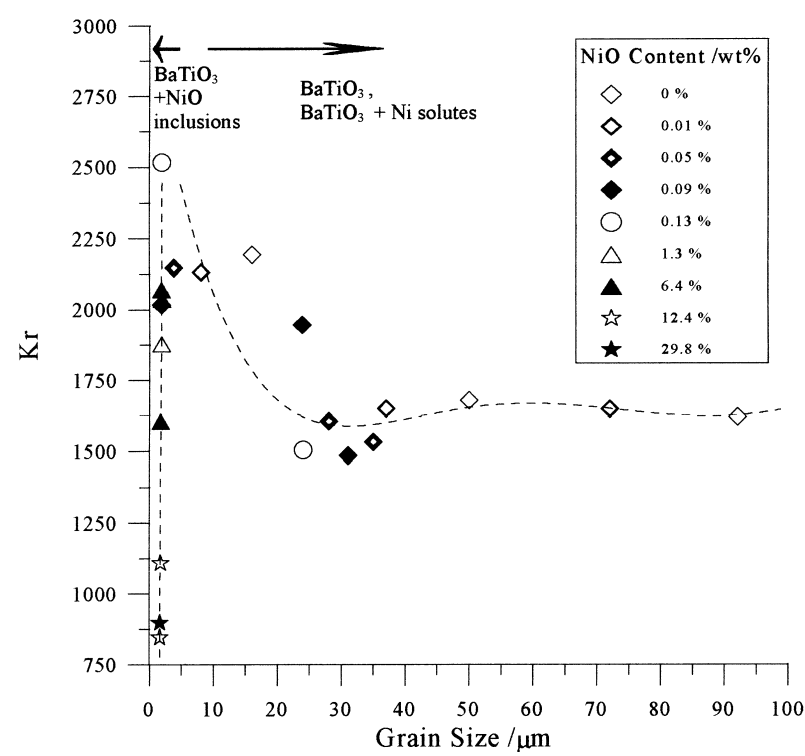

Fig. 7. The relative permittivity at room temperature $(\mathrm{Kr})$ as a function of grain size. The sintering temperature is between 1290 and $1370^{\circ} \mathrm{C}$.

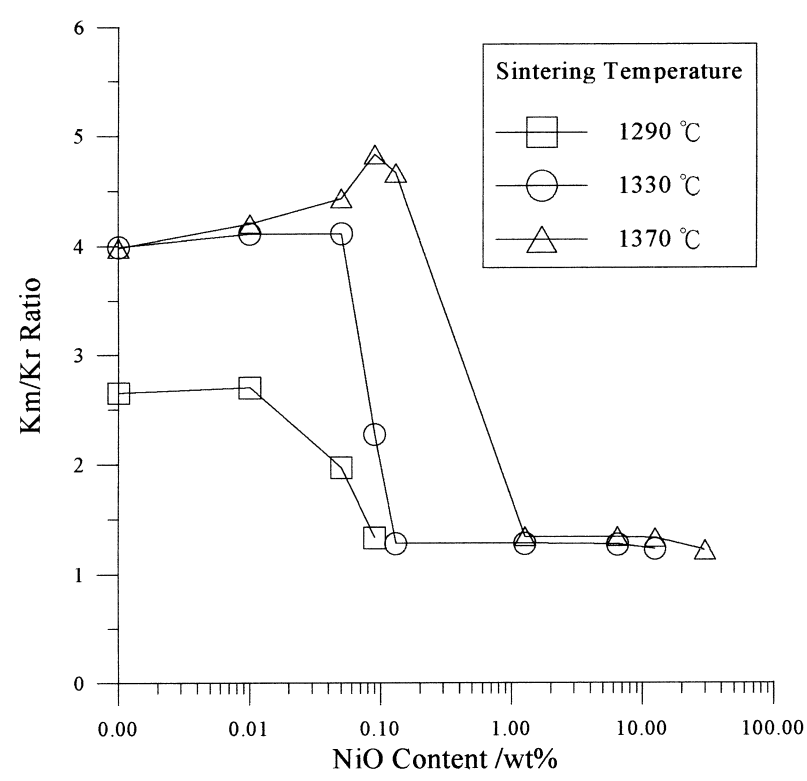

Fig. 8. The $K m / K r$ ratio of $\mathrm{NiO}$-doped $\mathrm{BaTiO}_{3}$ as a function of $\mathrm{NiO}$ content. 
temperature curve indicates that the diffusion phase transition (DPT) phenomenon exists in the $\mathrm{NiO}$ inclusions containing $\mathrm{BaTiO}_{3}$.

The relative permittivity at the Curie temperature, $K m$, strongly depends on the size of $\mathrm{BaTiO}_{3}$ grains as observed in Fig. 5. The figure shows that the $\mathrm{Km}$ decreases with the decrease of grain size. Martirena et al. [16] proposed that the stresses due to phase transformation become more difficult to release as the grain size decreases. The suppression of $K m$ for the finegrained specimens is resulted from the increase of internal stresses. The presence of non-ferroelectric $\mathrm{NiO}$ phase can also reduce the $K m$ value. The $K m$ is thus decreased with increasing amount of $\mathrm{NiO}$ and with decreasing of grain size.

The relative permittivity at room temperature, $K r$, is shown as a function of $\mathrm{NiO}$ content in Fig. 6. The $K r$ of undoped $\mathrm{BaTiO}_{3}$ is decreased as the sintering temperature is higher than the eutectic temperature $\left(\sim 1312^{\circ} \mathrm{C}\right)$. The formation of eutectic liquid and the precipitation of $\mathrm{Ba}_{6} \mathrm{Ti}_{17} \mathrm{O}_{40}$ phase degrade the $K r$. The relative permittivity decreases slightly with the increase of $\mathrm{NiO}$ content as the content is below the solubility limit. However, the $K r$ value increases significantly as the $\mathrm{NiO}$ content approaches the solubility limit. The $K r$ value then decreases as $\mathrm{NiO}$ inclusions are presented. The $\mathrm{Kr}$ values are shown as a function of grain size in Fig. 7. The $K r$ shows little dependence on grain size as the grain size is larger than $20 \mu \mathrm{m}$. However, there is an obvious increase of $K r$ as the size of grains approaches $2 \mu \mathrm{m}$. This phenomenon is similar to the results for $\mathrm{BaTiO}_{3}$. It was related to the decrease of $90^{\circ}$ domain width by Arlt et al. [1]. The size of $\mathrm{BaTiO}_{3}$ grains is significantly reduced as $\mathrm{NiO}$ is added (Fig. 3). Furthermore, the width of the $90^{\circ}$ domain in $\mathrm{NiO}$-doped

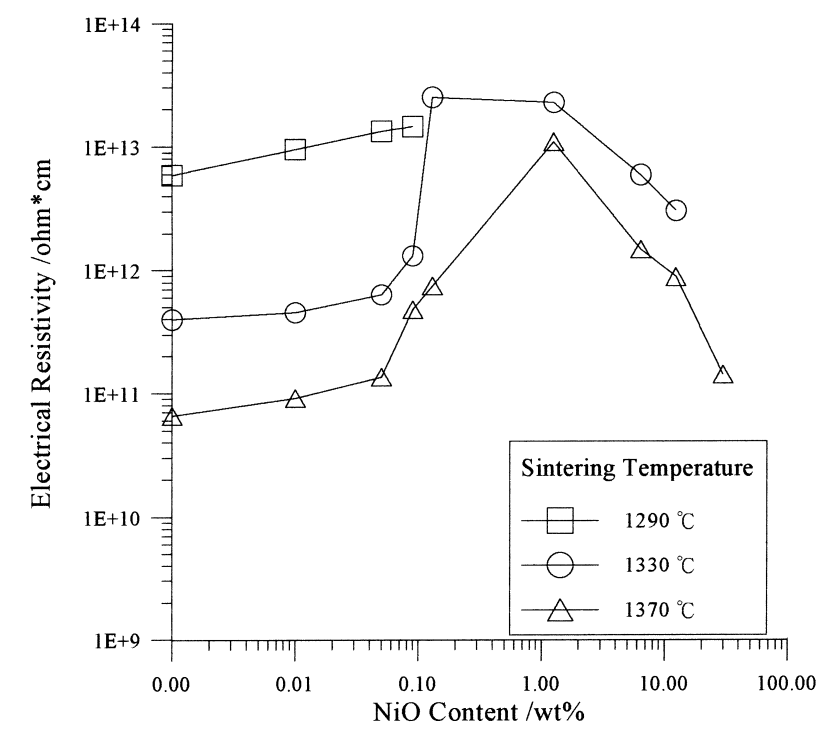

Fig. 9. The electrical resistivity of $\mathrm{NiO}$-doped $\mathrm{BaTiO}_{3}$ as a function of $\mathrm{NiO}$ content.
$\mathrm{BaTiO}_{3}$ is also decreased as $\mathrm{Ni}$ is soluble in $\mathrm{BaTiO}_{3}$ (Fig. 2). The increase of $K r$ (the right-hand side of Fig. 7 may be resulted from the decrease of $90^{\circ}$ domain width. For the left-hand side of Fig. 7, the relative permittivity of doped $\mathrm{BaTiO}_{3}$ decreases with the increase of the amount of non-ferroelectric $\mathrm{NiO}$ inclusions. It is due to the low relative permittivity of $\mathrm{NiO}$ phase.

For most of the specimens, the dissipation factor at room temperature is less than $2 \%$. The dissipation factor increases with the increase of porosity. This phenomenon is caused by the adsorption of moisture on the pore surface [17]. On the other hand, the dissipation factor increases significantly as $\mathrm{NiO}$ content is high. It may be due to the dissipation factor of non-ferroelectric $\mathrm{NiO}$ phase is high.

The $K m / K r$ ratio is shown as a function of $\mathrm{NiO}$ content in Fig. 8. The increase of $\mathrm{Km} / \mathrm{Kr}$ ratio in undoped $\mathrm{BaTiO}_{3}$ sintered at a temperature higher than $1312^{\circ} \mathrm{C}$ may be due to the formation of the eutectic liquid. However, the $\mathrm{Km} / \mathrm{Kr}$ ratio drops significantly when $\mathrm{NiO}$ content changes from 0.09 to $0.13 \mathrm{wt} \%$. These values correspond to the reported solubility limit of $\mathrm{NiO}$ in $\mathrm{BaTiO}_{3}$ [11]. The solubility limit of $\mathrm{NiO}$ in $\mathrm{BaTiO}_{3}$ has been determined by measuring the lattice parameter $c / a$ ratio with a XRD analysis technique [11]. The curves in Fig. 8 are surprisingly similar to the curves of lattice parameter $c / a$ ratio. It implies that the $K m / K r$ ratio can also be used to determine the solubility limit of $\mathrm{NiO}$ in $\mathrm{BaTiO}_{3}$. The $\mathrm{NiO}$ content for dropping the $K m / K r$ ratio is increased with the increase of sintering temperature. Fig. 8 suggests that the solubility limit of $\mathrm{NiO}$ in $\mathrm{BaTiO}_{3}$ is increased with the increase of sintering temperature. The figure also shows that the $\mathrm{Km} / \mathrm{Kr}$ ratio approaches unity as $\mathrm{NiO}$ second phase is presented. The

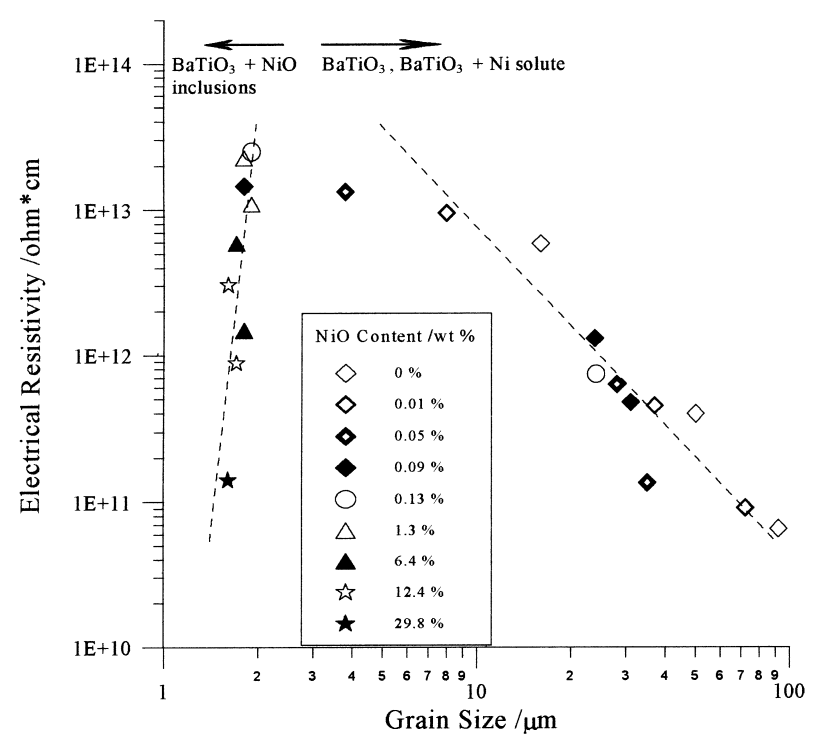

Fig. 10. The electrical resistivity as a function of grain size. 
low value of $K m / K r$ ratio is typical for the materials with diffuse phase transition (DPT).

The electrical resistivity of NiO-doped $\mathrm{BaTiO}_{3}$ is shown as a function of $\mathrm{NiO}$ content in Fig. 9. The resistivity is increased as the $\mathrm{NiO}$ content is below the solubility limit. The resistivity as a function of grain size is shown in Fig. 10. The right-hand side of the figure shows the results for $\mathrm{BaTiO}_{3}$ and $\mathrm{BaTiO}_{3}$ with $\mathrm{Ni}$ solute. The resistivity increases with the decrease of grain size as the $\mathrm{NiO}$ content is below the solubility. In other words, the resistivity is enhanced as the grain boundary area is increased. The $\mathrm{Ni}$ solute may segregate at the grain boundaries of $\mathrm{BaTiO}_{3}$, the grain boundary resistivity may thus be increased. The resistivity of doped $\mathrm{BaTiO}_{3}$ decreases with the increases of the amount of $\mathrm{NiO}$ inclusions (the left-hand side of Fig. 10). The reported value for the electrical resistivity of $\mathrm{NiO}$ is relatively low [18]. The presence of $\mathrm{NiO}$ second phase can thus reduce the resistivity of the doped $\mathrm{BaTiO}_{3}$.

\section{Conclusions}

The relationships between the microstructure and electrical properties of $\mathrm{NiO}$-doped $\mathrm{BaTiO}_{3}$ are investigated. The solubility limit of $\mathrm{NiO}$ in $\mathrm{BaTiO}_{3}$ is around $0.13 \mathrm{wt} \%$. The formation of eutectic liquid phase and $\mathrm{Ba}_{6} \mathrm{~T}_{17} \mathrm{O}_{40}$ precipitates degrades the relative permittivity at room temperature. However, the size of $\mathrm{BaTiO}_{3}$ grains is decreased as $\mathrm{NiO}$ is dissolved into $\mathrm{BaTiO}_{3}$. The relative permittivity at room temperature of the Ni-solute containing $\mathrm{BaTiO}_{3}$ is thus better than that of the undoped one. The relative permittivity at the Curie temperature is decreased instead due to the decrease of grain size. The $\mathrm{Ni}$ solute can also enhance the grain boundary resistivity. The relative permittivity and resistivity of $\mathrm{NiO}$ are low. The relative permittivity and resistivity of $\mathrm{BaTiO}_{3}$ reach its highest values as $\mathrm{NiO}$ content approaches its solubility limit. Although the existence of $\mathrm{NiO}$ inclusions reduces the relative permittivity, their presence also decreases the temperature sensitivity of the doped $\mathrm{BaTiO}_{3}$.

\section{References}

[1] G. Arlt, D. Hennings, G. de With, Dielectric properties of finegrained barium titanate ceramics, J. Appl. Phys 58 (1985) 1619-1625.

[2] W.R. Buessem, L.E. Cross, A.K. Goswami, Phenomenological theory of high permittivity in fine-grained barium titanate, J. Am. Ceram. Soc. 49 (1966) 33-36.

[3] H. Mostaghaci, R.J. Brook, Microstructure development and dielectric properties of fast-fired $\mathrm{BaTiO}_{3}$ Ceramics, J. Mater. Sci. 21 (1986) 3575-3580.

[4] H.G. Graham, N.M. Tallan, K.S. Mazdiyasni, Electrical properties of high-purity polycrystalline barium titanate, J. Am. Ceram. Soc. 54 (1971) 548-553.

[5] A. Yamaji, Y. Enomoto, K. Kinoshita, T. Mrakami, Preparation, characterization, and properties of Dy-doped small-grained $\mathrm{BaTiO}_{3}$ Ceramics, J. Am. Ceram. Soc. 60 (1977) 97-101.

[6] M. Kahn, Preparation of small-grained and large-grained ceramics from Nb-doped $\mathrm{BaTiO}_{3}$, J. Am. Ceram. Soc. 54 (1971) 452-454.

[7] K.S. Mazdiyasni, L.M. Brown, Microstructure and electrical properties of $\mathrm{Sc}_{2} \mathrm{O}_{3}$-doped, rare-earth-oxide-doped, and undoped $\mathrm{BaTiO}_{3}$, J. Am. Ceram. Soc. 54 (1971) 539-543.

[8] D.A. Payne, H.U. Anderson, Inhibition of grain growth in barium titanate, J. Am. Ceram Soc. 50 (1967) 491-503.

[9] A.C. Caballero, J.C. Fernandez, C. Moure, P. Duran, ZnOdoped $\mathrm{BaTiO}_{3}$ : microstructure and electrical properties, Journal of the European Ceramic Society 17 (1997) 513-523.

[10] Y. Sakabe, Dielectric materials for base-metal multilayer ceramic capacitors, Am. Ceram. Soc. Bull. 66 (1987) 1338-1341.

[11] W.H. Tzing, W.H. Tuan, Effect of $\mathrm{NiO}$ addition on the sintering and grain growth behaviours of $\mathrm{BaTiO}_{3}$, Ceramics International 25 (1) (1999) 69-75.

[12] H.M. O'Bryan, J. Thomson, Phase equilibria in the $\mathrm{TiO}_{2}$-rich region of the system $\mathrm{BaO}-\mathrm{TiO}_{2}$, J. Am. Ceram. Soc. 57 (1974) 522-526.

[13] W.H. Tuan, E. Gilbart, R.J. Brook, Sintering of heterogeneous ceramic compacts, 1. Alumina/alumina, J. Mater. Sci. 24 (1989) $1062-1068$.

[14] H. Ihrig, The phase stability of $\mathrm{BaTiO}_{3}$ as a function of doped 3d elements: an experimental study, J. Phys. C: Solid State Phys. 11 (1978) 819-827.

[15] H. Emoto, J. Hojo, Sintering and dielectric properties of $\mathrm{BaTiO}_{3-}$ Ni composite ceramics, J. Ceram. Soc. Japan, Inter. Ed. 100 (1992) 553-557.

[16] H.T. Martirena, J.C. Burfoot, Grain-size effects on properties of some ferroelectric ceramics, J. Phys. C: Solid State Phys. 7 (1974) 3182-3192.

[17] T.T. Fang, H.L. Hsieh, F.S. Shiau, Effects of pore morphology and grain size on the dielectric properties and tetragonal-cubic phase transition of high-purity barium titanate., J. Am. Ceram. Soc. 76 (1993) 1205-1211.

[18] W.D. Kingery, H.K. Brown, D.R. Uhlmann, Electrical conductivity, in: Introduction to Ceramics, John Wiley and Sons, New York, 1976, pp. 867-869. 